\title{
Applying the BurKe-Litwin MOdel as a DiAgnOSTIC FRAMEWORK FOR ASSESSING ORGANISATIONAL EFFECTIVENESS
}

Authors:

Nico Martins ${ }^{1}$

Melinde Coetzee ${ }^{1}$

\section{Affiliations:}

${ }^{1}$ Department of Industrial and Organisational Psychology, University of South Africa, South Africa

\section{Correspondence to:} Nico Martins

e-mail:

martin@unisa.ac.za

\section{Postal address:}

Department of Industrial and Organisational

Psychology, PO Box 392,

UNISA, 0003, South Africa

\section{Keywords:}

Burke-Litwin model of organisational performance and change; organisational diagnosis; organisational effectiveness; transactional factors; transformational factors

Dates:

Received: 19 Nov. 2008 Accepted: 16 July 2009 Published: 11 Sept. 2009

How to cite this article: Martins, N., \& Coetzee, M. (2009). Applying the Burke-Litwin model as a diagnostic framework for assessing organisational effectiveness. SA Journal of Human Resource Management/SA Tydskrif vir Menslikehulpbronbestuur, 7(1), Art. \#177, 13 pages. DOI: 10.4102/sajhrm.v7i1.177

This article is available at: http://www.sajhrm.co.za

C 2009 . The Authors. Licensee: OpenJournals Publishing. This work is licensed under the Creative Commons Attribution License.

\begin{abstract}
This exploratory study investigated the utility of the Burke-Litwin model as a diagnostic framework for assessing the factors affecting organisational effectiveness. The research setting consisted of an international company, with a population comprising representatives of more than 17 different nationalities. The purposive sampling method was used to involve employee participants $(\mathrm{N}=$ $147)$ in focus groups and executive managers $(\mathrm{N}=11)$ in semi-structured probing interviews. The factors identified related to both the transformational and transactional dimensions of the Burke-Litwin model. The findings add to the existing literature on factors causing organisational effectiveness and ineffectiveness in cross-cultural organisational contexts.
\end{abstract}

\section{INTRODUCTION}

Organisations are continually searching for innovative ways of enhancing competitiveness, as evolving external forces, such as changing demographics, globalisation and technology, require managers to rapidly rethink and retool their organisational management strategies (Whitfield \& Landeros, 2006). In this regard, organisational leaders and theorists increasingly view organisational diagnosis as a key element in developing and maintaining competitive advantage (Lee \& Brower, 2006). Although the current literature on organisations offers a diverse array of theories on the construct of organisational effectiveness, virtually all such theories acknowledge the importance of organisational effectiveness and its relation to improved organisational performance (Baruch \& Ramalho, 2006; Lee \& Brower, 2006). Organisational effectiveness illustrates the soundness of an organisation's culture, processes and structure in terms of its overall system performance (French \& Bell, 1999). The practical use of assessing organisational effectiveness stems from the intent to analyse the present state of an organisation to improve the performance of the organisation in accordance with diagnostic findings (Lee \& Brower, 2006). Assessing organisational effectiveness by means of a well-planned and well-executed diagnostic process is, therefore, generally assumed to form part of a broad organisational management strategy aimed at improving overall system management (Cummings \& Worley, 2005; French \& Bell, 1999). The use of such a diagnostic process provides an organisation with the systematic knowledge that it needs to design a set of appropriate intervention activities that should improve overall organisational effectiveness (Van Tonder \& Dietrichsen, 2008).

Diagnosis entails understanding a system's current functioning. More specifically, Harrison (cited in Van Tonder \& Dietrichsen, 2008:137) describes organisational diagnosis as consisting of investigations that draw on concepts, models and methods from the behavioural sciences. Such investigations are generally aimed at examining an organisation's current state, at helping clients find ways to solve problems, or at enhancing organisational effectiveness. Organisational diagnosis is also regarded as a collaborative process embarked on between organisation members and an organisational development (OD) consultant. The process involves collecting pertinent information about current operations, analysing the data obtained, and drawing conclusions regarding potential change and improvement (Cummings \& Worley, 2005; Slocum \& Hellriegel, 2007). Empirical research conducted in the past indicates that successful employee involvement efforts using an organisational diagnostic process can have a substantial impact on the financial productivity of an organisation (Cummings \& Worley, 2005; Huselid, 1995; Ostroff, 1995). A well-executed organisational diagnostic process fosters and promotes a continuous learning environment that not only impacts on the organisation's ability to rapidly adapt to change, but which also positively affects its bottom-line organisational performance and overall effectiveness (Kontoghiorghes, Awbrey \& Feurig, 2005).

\section{Objectives of the study}

The current exploratory study aimed to investigate the utility of the Burke-Litwin model as a diagnostic framework for assessing the factors affecting organisational effectiveness in a cross-cultural research setting. In the context of the particular research setting, it was important to identify a well-researched diagnostic model that focused on environmental impact and organisational performance, as well as on change and effectiveness, and which could be applied in a cross-cultural context. According to Jones and Brazzel (2006), there is no best diagnostic model. The model used depends on the situation and the practitioner's style and lenses. Burke (cited in Jones \& Brazzel, 2006) mentions three criteria for selecting a diagnostic model: Firstly, the model should be one that the OD practitioner thoroughly understands and is at ease with; secondly, it should fit the client organisation as closely as possible; and, thirdly, the model should be sufficiently comprehensive to enable data to be gathered about the organisation within the model's parameters, and without missing out on any key details concerned.

As shown in Table 1, several of the most frequently used models (Jones \& Brazzel, 2006) were considered, taking the foregoing criteria and the strengths and limitations of each model into consideration. Models such as the Weisbord model, the McKinsey seven-S model and the Galbraith STAR model were found to be too simplistic for the purpose of the current study (Jones \& Brazzel, 2006). Moreover, the Freedman Swamp model of socio-technical systems and the Nadler Tushman congruence model were found to be too complex to address the aims of the study. In terms of 
TABLE 1

Comparing diagnostic models

\begin{tabular}{|c|c|c|c|c|}
\hline MODELS & WHEN TO APPLY & STRENGTHS & LIMITATIONS & EVALUATION \\
\hline Weisbord model & $\begin{array}{ll}\text { - } & \text { Environment is not a } \\
\text { significant factor } \\
\text { Simplicity and speed of } \\
\text { diagnosis are important }\end{array}$ & $\begin{array}{ll}\cdot & \text { Well-known } \\
\dot{*} & \text { Easy to explain } \\
& \text { Helps identify and focus } \\
\text { priorities }\end{array}$ & $\begin{array}{ll}\cdot & \text { Does not show } \\
\text { interdependencies clearly } \\
\text { - } & \text { Too simplistic } \\
\text { Does not examine } \\
\text { environmental influences }\end{array}$ & $\begin{array}{l}\text { Does not include change } \\
\text { and distinguish between } \\
\text { transformational and } \\
\text { transactional diagnosis in } \\
\text { organisational behaviour and } \\
\text { change }\end{array}$ \\
\hline $\begin{array}{l}\text { Nadler Tushman congruence } \\
\text { model }\end{array}$ & $\begin{array}{l}\text { - A comprehensive analysis is } \\
\text { required } \\
\text { A system perspective is } \\
\text { required }\end{array}$ & $\begin{array}{l}\text { - Suggests cause-effect } \\
\text { relationships } \\
\text { Highlights both mismatches } \\
\text { and congruence } \\
\text { Considers the influence of the } \\
\text { external environment }\end{array}$ & $\begin{array}{l}\text { In the short term, } \\
\text { congruence can lead to } \\
\text { improved effectiveness and } \\
\text { performance, but in the } \\
\text { longer term congruence can } \\
\text { fuel resistance to change } \\
\text { Paints a picture that might be } \\
\text { too complex and difficult to } \\
\text { understand }\end{array}$ & $\begin{array}{l}\text { Too difficult to understand; } \\
\text { congruence in the long term } \\
\text { can be problematic }\end{array}$ \\
\hline $\begin{array}{l}\text { Freedman Swamp model of } \\
\text { sociotechnical systems }\end{array}$ & $\begin{array}{l}\text { - A comprehensive analysis is } \\
\text { required } \\
\text { A specific, explicit } \\
\text { comprehensive assessment } \\
\text { is required }\end{array}$ & $\begin{array}{l}\text { - Comprehensive } \\
\text { Considers many of the } \\
\text { categories, linkages and } \\
\text { boundaries that occur in } \\
\text { organisations }\end{array}$ & $\begin{array}{l}\text { Appears complicated } \\
\text { Need to create unique } \\
\text { meta-models that fit the } \\
\text { organisation }\end{array}$ & Too complicated \\
\hline McKinsey seven-S model & $\begin{array}{l}\text { A multivariable framework } \\
\text { is required to determine why } \\
\text { organisations are not linking } \\
\text { capability and competence }\end{array}$ & $\begin{array}{l}\text { Explains why renewal is a } \\
\text { complex set of processes } \\
\text { Can be linked to the 7-C } \\
\text { framework of planning }\end{array}$ & $\begin{array}{ll}\text { - } & \text { Too simplistic } \\
\text { - } & \text { Looks gimmicky }\end{array}$ & $\begin{array}{l}\text { - Too simplistic for analysis } \\
\text { required }\end{array}$ \\
\hline Galbraith STAR model & $\begin{array}{l}\text { A review of organisation } \\
\text { design is indicated } \\
\text { The hierarchy seems } \\
\text { overloaded } \\
\text { Extensive change is } \\
\text { occurring }\end{array}$ & $\begin{array}{ll}\text { - } & \text { Systemic } \\
& \text { Sees an organisation as an } \\
\text { information-processing entity }\end{array}$ & $\begin{array}{l}\text { - Does not include the external } \\
\text { environment as an influencer } \\
\text { - Too simplistic }\end{array}$ & $\begin{array}{l}\text { Neither includes change } \\
\text { nor distinguishes between } \\
\text { transformational and } \\
\text { transactional diagnosis in } \\
\text { organisational behaviour and } \\
\text { change }\end{array}$ \\
\hline $\begin{array}{l}\text { Burke-Litwin model of } \\
\text { organisational performance and } \\
\text { change }\end{array}$ & $\begin{array}{l}\text { A practical utility is required } \\
\text { Need to see how } \\
\text { organisational performance } \\
\text { and effectiveness are } \\
\text { affected } \\
\text { Need to see how change can } \\
\text { be influenced } \\
\text { A cross-cultural application } \\
\text { is required }\end{array}$ & $\begin{array}{l}\text { Explains linkages } \\
\text { Shows cause-and-effect } \\
\text { relationships between } \\
\text { organisation's internal and } \\
\text { external environments } \\
\text { Distinguishes between the } \\
\text { role of transformational and } \\
\text { transactional dynamics in } \\
\text { organisational behaviour and } \\
\text { change }\end{array}$ & $\begin{array}{l}\text { Complexity (as in relation to } \\
\text { the intricacy of organisational } \\
\text { phenomena) }\end{array}$ & $\begin{array}{l}\text { - Fits most criteria pertaining to } \\
\text { the current study } \\
\text { - Of practical usefulness in } \\
\text { cross-cultural research setting } \\
\text { - Well-researched } \\
\text { - Empirical evidence of addition } \\
\text { of value to outcomes of an } \\
\text { organisational diagnostic } \\
\text { process }\end{array}$ \\
\hline
\end{tabular}

Source: Based on Cummings \& Worley (2005); French \& Bell (1999); Jones \& Brazzel (2006); Van Tonder \& Roodt (2008); Van Tonder \& Dietrichsen (2008)

Tushman's model, Jones and Brazzel (196) also point out that in the short term, congruence can lead to improved effectiveness and performance, whereas, in the longer term, congruence can fuel resistance to change.

The well-known Burke-Litwin model (Burke \& Litwin, 1992) was regarded as fitting all three of the stated criteria. Furthermore, the Burke-Litwin model of organisational performance and change is founded on a functional cause-and-effect framework. The model explains linkages that hypothesise how organisational performance and overall effectiveness are affected, as well as how deliberate and effective change can be influenced. The model is reported to clearly show causeand-effect relationships between the organisation's internal and external environments, aimed at explaining their link to organisational effectiveness (Burke \& Litwin, 1992; Chawane, Van Vuuren \& Roodt, 2003). Although the model is also regarded as quite complex, its ability to add value to the outcomes of the organisational diagnostic process in cross-cultural research settings (Furnham \& Gunter, 1993; Howard, 1994; Jones \& Brazzel, 2006) was regarded as a strenth

\section{The Burke-Litwin model of organisational performance and change}

Researchers conducting organisational diagnosis generally agree that organisational effectiveness should be viewed from a systems perspective using a multidimensional approach in assessing the factors affecting an organisation's performance and overall effectiveness (Baker \& Maddux, 2005; Baruch \& Ramalho, 2006; Burke \& Litwin, 1992; Cummings \& Worley, 2005; Lee \& Brower, 2006). In this regard, the Burke-Litwin model (Burke \& Litwin, 1992) is seen to serve as a conceptual framework, which describes the relationships between different features of the organisation, as well as its context and effectiveness (Cummings \& Worley, 2005). Taking into consideration the complex nature of organisational phenomena, change models, such as the Burke-Litwin model, provide a taxonomy of key organisational dimensions that serves to guide data collection and diagnosis (Chawane et al., 2003).

According to Burke and Litwin (1992), change models are not meant to be prescriptive, rather they are meant to provide a means to diagnose, plan and manage change. Beer (cited in Chawane et al.,2003, p. 73) regards organisational change models as arbitrary, convenient shorthand methods of explaining organisational challenges, which can facilitate the process of planning how such challenges can be dealt with efficiently. Change models are also used to explain an organisational diagnostic method by which organisational phenomena may be understood and, therefore, managed to improve overall organisational performance and effectiveness (Chawane et al., 2003).

The Burke-Litwin model (Burke \& Litwin, 1992) is a model that predicts behaviour and performance consequences. It deals with cause (organisational conditions) and effect (resultant performance), serving as a guide not only for organisational diagnosis, but also for planned managed organisational change (French \& Bell, 1999). According to Furnham and Gunter (1993), the Burke-Litwin model is the best-known and most influential model for looking at the role of organisational climate in business performance. French and Bell consider the model as playing a significant role in thinking about planned change. Kraut (1996) not only describes the model as comprehensive, but also regards it as based on sound theory and research. According to him, the model enhances the efficacy of an organisational diagnosis, as well as serving as a guide to actions resulting from the diagnosis.

The Burke-Litwin model (Burke \& Litwin, 1992) highlights two distinct sets of organisational dynamics. One set is primarily associated with the transactional level of human behaviour, or 
the everyday interactions and exchanges that create the climate of the organisation. The second set of dynamics is concerned with processes of human transformation, amounting to sudden 'leaps' in behaviour. Such transformational processes are required for genuine change to take place in the culture of an organisation (French \& Bell, 1999; Jones \& Brazzel, 2006). The transformational variables refer to those areas in which alteration is usually caused by interaction with environmental forces (both within and without the o rganisation), and which therefore require entirely new behaviour sets on the part of organisational members. According to Burke and Litwin, the external environment affects transformational factors, which are identified as the organisational mission and strategy, leadership and culture. The transformational factors, in turn, affect the transactional factors, which are identified as the organisational structure, systems, management practices and climate. Both types of factors reciprocate, and eventually impact on, individual and organisational performance and overall effectiveness (Chawane et al., 2003).

As shown in Figure 1, the following variables form the basic building-blocks of the Burke-Litwin model (Howard, 1994).

\section{Transformational factors affecting organisational performance and effectiveness}

- External environment: Any outside condition or situation that influences the performance of the organisation. Such conditions include marketplaces, world financial conditions, political/governmental circumstances, competition and customers.

- Vision, mission and strategy: What employees believe to be the central purpose of the organisation and how the organisation intends to achieve its purpose over an extended period of time.

- Leadership: Behaviour that encourages others to take necessary actions, including perceptions of leadership style, practices and values.

- Organisational culture: 'The way we do things around here.' Culture is the collection of overt and covert rules, values and principles that guide organisational behaviour and that have been strongly influenced by the organisation's history, custom and practice.

- Individual and organisational performance: The measurable outcomes or results, with their relevant indicators of effort and achievement. Such indicators might include productivity, customer or staff satisfaction, profit and service quality, salary and benefits, and recognition.

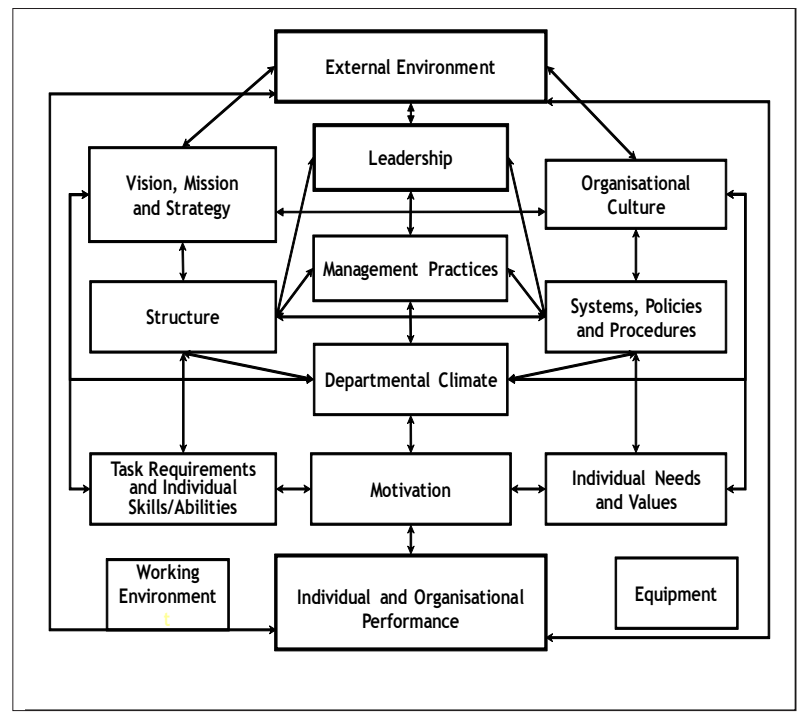

FIGURE 1

Adapted Burke-Litwin model (Burke \& Litwin, 1992)
Transactional factors affecting organisational performance and effectiveness

- Structure: The arrangement of functions and employees in specific areas and levels of responsibility, decision-making authority and relationships. Structure assures the effective implementation of the organisation's mission and strategy.

- Management practices: What managers do in the normal course of events in using the human and material resources at their disposal to carry out the organisation's strategy, including aspects such as managerial behaviour, work etiquette, professionalism, planning, communication and control.

- Systems (policies and procedures): Standardised policies and mechanisms that facilitate work. Systems primarily manifest themselves in the organisation's reward and control systems, such as in goal and budget development and standard operating procedures (SOPs).

- Departmental/work unit climate: The collective current impressions, expectations and feelings of the employees in their respective departments, which, in turn, affect their relations with their superiors, with one another, and with other departments. A positive work climate might serve to enhance retention rates, whereas a negative work climate might lead to a high employee turnover rate.

- Task requirements and individual skills/abilities: The behaviour, including specific skills and knowledge required for task effectiveness, enabling employees to accomplish the work assigned, for which they feel directly responsible. The job-person match entails elements of recruitment, selection, appointment and promotion.

- Individual needs and values: The specific psychological factors that validate individual actions or thoughts relating to stress, well-being, recreational activities and living conditions.

- Motivation: Aroused behavioural tendencies to move toward goals, take needed action and persist until satisfaction is attained form the net resultant motivation, meaning the resultant net energy generated by the sum of achievement, power, affection, discovery and other important human motives.

In the context of the current research, two additional dimensions (which relate to the transactional aspects of the Burke-Litwin model) were added after identifying the patterns and themes that emerged from the organisational diagnosis:

- Equipment: The tools to do the job and the quality of available technology.

- Working environment: Facilities such as the buildings, offices, staff cafeteria and recreational facilities for the staff.

Burke and Litwin (1992) propose that interventions directed at leadership, mission and strategy, and organisational culture produce transformational or fundamental change in the organisation's culture. Interventions directed at management practices, structure and systems produce transactional change, or change in the organisational climate. The Burke-Litwin model helps OD practitioners to size up the change situation, to determine the kind of change (whether transformational or transactional) required and then to target interventions toward factors of the organisation that will produce the desired change (French \& Bell, 1999). The research undertaken by Furnham and Gunter (1993), Howard (1994) and Jones and Brazzel (2006) suggests that the model performs as intended.

\section{Research approach}

\section{RESEARCH DESIGN}

An organisational diagnostic approach was decided upon, as such an approach specifically suits research taking place in a natural and unique setting, such as was the case with the hotel company concerned in the current study. Organisational diagnosis is central to the science and practice of $\mathrm{OD}$, which primarily uses action research methodology (Van Tonder \& Dietrichsen, 2008). The OD practitioner acts as a diagnostician 
in utilising action research methodology, including the use of diagnostic models and various quantitative and/or qualitative diagnostic methods, instruments and techniques, as well as focused diagnostic interventions, in a context with unique features (Van Tonder \& Dietrichsen, 2008).

Organisational diagnosis is essentially a data-gathering method which involves extracting appropriate and relevant data that describes the shortfall between the actual, current system functioning and the desired state of functioning, in which the client (or client system) typically articulates perceived difficulties and the desired future state. Diagnostic data are employed to develop or source methods and actions that will breach and reduce the 'gap' concerned (Cummings \& Worley, 2005; Van Tonder \& Dietrichsen, 2008). The general purpose of organisational diagnosis is to establish a valid, accurate and unobstructed view ('picture') of the organisation, which can be easily understood by all relevant stakeholder constituencies (Cummings \& Worley, 2005; Van Tonder \& Dietrichsen, 2008).

\section{Research strategy}

As the main objective of the study was to gather organisational data for diagnostic purposes, which entailed identifying those organisational factors causing organisational effectiveness or ineffectiveness in a cross-cultural setting, an action research strategy was employed. Action research is a well-established strategy in organisational diagnostic approaches aimed at systematic data-based problem-solving (Jackson, 2008). Such research focuses on planned change as a cyclical process, in which the initial research conducted into the organisation provides information that is obtained by means of the use of organisational diagnostic models, methods and techniques intended to guide subsequent improvement actions (Cummings \& Worley, 2005). The purpose of the action research effort generally dictates the scope, intensity and likely duration of the organisational diagnosis, which is agreed upon by the client system's representative prior to starting the action research process (Jackson, 2008).

In the context of the current study the scope of the diagnosis (and therefore the action research process) was narrow, of relatively short duration, and limited to identifying the factors causing the company to be effective or ineffective at the time of the diagnostic effort. The data were then fed back into the organisation, with a view to inform decision-making regarding improvement actions. The focal efforts, time and resources of the researcher were, therefore, directed at addressing the client's needs, while attempting to cover the broader contextual domain (that is, the cross-cultural context and external environmental features) that might have been found to influence the interpretation and meaning of the behavioural dynamics and problems surfacing during the diagnosis. Furthermore, as the focal point or target unit of diagnosis was the entire organisation, the Burke-Litwin model (Burke \& Litwin, 1992) relevant to organisational performance and change provided a sound framework within which to achieve the aims of the action research effort. The Burke-Litwin model, which is grounded in validated research, allows the researcher to interpret the presented data and to identify the factors and areas which, according to the model, underlie and inform the presented data in a scientifically accountable and reliable way (Furnham \& Gunter, 1993; Howard, 1994; Jones \& Brazzel, 2006).

\section{Research method}

Research setting

The research setting consisted of an international hotel group in the Middle East, with a population comprising more than 17 different nationalities (including Egyptian, Filipino, Dutch, Swedish, Canadian, South African, American and Bahraini). Although the staff complement was found to be very diverse, all the participants in the study were found to speak English relatively fluently, as English is the language in which the hotel conducts business.

\section{Entrée and the establishment of researcher roles}

The choice of organisational diagnostic (data-gathering) instruments was determined by the scope and aims of the diagnostic effort agreed on by the client. The researcher relied primarily on a combination of semi-structured interviews and focus groups to generate the data. Interviews and focus groups are useful in generating rich data on a range of subjects, thus creating a basis for ownership and post-diagnostic commitment to action (Van Tonder \& Dietrichsen, 2008).

The advantages of employing a diagnostic research methodology are numerous. Firstly, the role of the researcher (as the diagnostician) in the diagnostic process, which is to actively engage in the making of meaning from text or with the subject under study, allows the researcher to detect the nuances, uncertainties, emotional reactions and ambiguities characteristic of human interaction, which is missed in some quantitative analyses (Henning, Van Rensburg \& Smit, 2004; Smith, 2003). Moreover, since the researcher serves as the primary instrument of data collection and data analysis, comprehension can be broadened through conducting both non-verbal and verbal communication with the respondents. The diagnostic method also allows the researcher (in the role of diagnostician) to process the data immediately, to clarify and summarise material, to check with the respondents the accuracy of interpretation, and to explore unusual or unanticipated responses (Smith, 2003).

\section{Sample and sampling method}

Purposive sampling was used to ensure that employees from all departments and job levels were selected to participate in the focus groups. In addition, all 11 executive managers were individually interviewed in semi-structured probing interviews.

As a non-probability sampling procedure, purposive sampling implies that the probability of any particular member of the population being chosen is unknown (Struwig \& Stead, 2001). Purposive sampling occurs when the researcher looks for those who fit the criteria of 'desirable participants', as was the case in the current study. In the context of the study, the Human Resources (HR) Director contacted all the participants whom he wished to be respondents in the study and invited them to participate. Such a sampling methodology is in line with Waclawski and Church's (2002) proposal to conduct different focus groups for top management, for middle management and for non-managerial employees. The purpose of using such a methodology is to obtain a diverse and representative sample of employees, without jeopardising their degree of confidence and openness.

As shown in Table 2, a total of 147 employees from all levels of the organisation participated in the focus groups, with 11 executive managers being individually interviewed. Such participation yielded a sample of $29.5 \%$ of a population of 535 employees, which is regarded as more than adequate for a qualitative survey (Schurink, 2003). The educational qualifications of the focus groups' participants ranged from job grades 1 to 8 .

The respondents were selected from all 16 departments in the hotel. An equal number per department was invited to the focus groups. A middle manager from each department was also invited to participate in the study. The process ensured that all the departments were sufficiently covered in terms of employee selection and that the process of selection was perceived to be fair by all the employees at the hotel.

\section{Data collection methods Interviews}

Semi-structured probing interviews were used to collect data from the 11 executive managers for the purpose of the current 
TABLE 2

Number of participants, according to group and department $(N=158)$

\begin{tabular}{|c|c|c|}
\hline GROUP & DEPARTMENT & $\begin{array}{r}\text { NO. OF } \\
\text { PARTICIPANTS }\end{array}$ \\
\hline & $\begin{array}{l}\text { Executive managers (Semi-structured probing } \\
\text { interviews) }\end{array}$ & 11 \\
\hline 1. & Housekeeping and Laundry & 10 \\
\hline 2. & Maintenance & 9 \\
\hline 3. & Rooms Division - Group 1 (HK, Front Desk) & 10 \\
\hline 4. & Sales and Accounts & 9 \\
\hline 5. & Short-Service Group (Expatriates) & 10 \\
\hline 6. & Long-Service Group & 9 \\
\hline 7. & Rooms Division - Group 2 & 9 \\
\hline 8. & GICEC and Banqueting & 9 \\
\hline 9. & Ladies & 10 \\
\hline 10. & Kitchen & 9 \\
\hline 11. & Bars and Health Club & 10 \\
\hline 12. & Human Resources Administration and General & 10 \\
\hline 13. & Food and Beverage - Group 1 & 8 \\
\hline 14. & Middle Management - 0 Grade 9 & 6 \\
\hline 15. & Middle Management - Grades $10 \& 11$ & 10 \\
\hline \multirow[t]{3}{*}{16.} & Food and Beverage - Group 2 & 9 \\
\hline & Total (focus group participants) & 147 \\
\hline & TOTAL & 158 \\
\hline
\end{tabular}

research. A semi-structured interview consists of an investigator asking a set of scheduled questions, with the interview being guided, rather than dictated, by the schedule (Banister, Burman, Parker, Taylor \& Tindall, 1994). Probing or sensing interviews are regarded as an invaluable and powerful diagnostic tool for diagnostic applications in organisations (Roodt, 2008). Such an interview is conducted non-threateningly, resulting from the establishment of a trustful relationship with the participants concerned, which enables the purpose of the interview and the utilisation of the data to be gathered to be explained to them. The probing interview, when applied within a purposive sampling context, enables the interviewer (or diagnostician) to probe more deeply into the identified themes and to purposively sample other interviewees, in order to follow up on identified cues or issues (Roodt, 2008).

Using semi-structured probing interviews to collect data has numerous advantages. Firstly, such interviews provide the researcher with the opportunity to establish relationships with the participants, in order to encourage the development of a sense of trust and cooperation, which is often needed to probe sensitive areas. Secondly, the probing interview helps participants to interpret the questions appropriately. Thirdly, the semi-structured probing interview allows flexibility in determining the wording and sequence of the questions asked, as such an interview setting allows for personal interaction and the opportunity to follow up on incomplete or vague responses (Rosnow \& Rosenthal, 1996; Welman \& Kruger, 2001). The disadvantages of using probing interviews include the high level of demands made on time, costs, interviewer skills, data analysis and interpretation (Van Tonder \& Dietrichsen, 2008; Welman \& Kruger, 2001).

In the context of the current study, each of the 11 executive managers was interviewed individually at their offices or in one of the meeting rooms made available. The interviews with the participants were scheduled to last an hour. The duration of the interviews varied for the different participants. The
TABLE 3

List of interview questions

1. How would you describe the hotel to a friend (the culture; the way you do
things; what you do well; your customer focus)?
2. In general, what outside conditions, such as competition, market changes,
etc. have the biggest influence on the hotel?
3. Do you think that the hotel is correctly positioned to meet these challenges?
4. Are the hotel's business objectives driven primarily by your customer focus?
5. From your point of view, what do you experience as the best products and
6. How does the hotel's service and product quality compare to that of your
7. How do you view the competence and professionalism of the staff?
8. Are decisions made 'close to the customer'?
9. How do you experience the balance between work and personal life?
10. Do you think that all the employees are treated equally and fairly?
11. Do the employees understand the service standards?
12. Do the managers in general understand the diverse workforce?
13. Does the hotel cater sufficiently for the recreational and social activities of
its staff?
14. If you had the opportunity, what would you change at the hotel to improve
the overall performance?
15. Do you have any other comments?

average time of each interview, however, was 50 minutes. The purpose of the interview was explained, and 15 semistructured questions were asked of the managers concerned. In 10 instances, scales were added to the questions to enable the researchers to quantify the responses, so that the interviewees' responses could be probed more deeply. As shown in Table 3, the interview guide consisted of 15 questions, which focused more strategically on aspects such as the culture of the hotel company, anticipated future competition, business objectives, the quality of service and the products made available, the professionalism of the staff, work/life balance, the equality of conditions, the service standards, workforce diversity and the social activities of staff. Opportunities were also given for additional comments.

\section{Focus groups}

Focus groups are regarded as a variant of the unstructured interview, as the essence of such groups is a group interview (Roodt, 2008; Rothwell \& Sullivan, 2005). Roodt regards the use of focus groups as a powerful organisational diagnostic tool for establishing a shared sense of a problem, as well as its impact and the solutions required. The downside of a focus group is that it can contribute to 'groupthink', encouraging the dominant voice in such a group to influence others to express themselves in the same way, regardless of whether such expression really reflects how they think (Rothwell \& Sullivan, 2005). Moreover, superficial data, which might not fully reveal the depth of the problem, might be generated. The status of some group members might also influence the decision outcomes (Roodt, 2008).

For the purpose of the diagnostic effort, the following four questions were posed to the participants during the focus groups to ensure validity (that is, to elicit the desired level and range of responses) and reliability of responses (that is, to ensure that the questions would consistently be understood in the same way by all participants):

- What are the characteristics of an employee of choice? (Question 1)

- What excites you about your work (makes you happy) at the hotel? (Question 2)

- What would you change at the hotel if you had the opportunity? (Question 3) 
- What does the hotel do particularly well? (Question 4)

A brief introduction was provided for the participants. Thereafter, the purpose of the session, the ground rules for the session, and the roles of the facilitators were explained. The researchers controlled the possibility of groupthink as follows:

- Each of the four questions was separately listed on flipchart paper.

- The participants were requested to write down their answers individually on post-it notepaper, without discussing the answers with their colleagues. Such discussion was discouraged in order to maintain the confidentiality of the exercise.

- The post-it notes, after being collected by the researchers, were quickly reviewed and provisionally grouped per managerial dimension/theme identified in terms of the Burke-Litwin model (Burke \& Litwin, 1992). The notes were then stuck onto the flip chart.

- All misunderstandings or unclear answers were then discussed. Notes were made on the post-it notepaper, or on separate sheets of paper. During this phase, the contributions made by the dominant participants were facilitated and the participation of those participants who appeared to be shy was encouraged.

- The above process was repeated for each of the four questions.

The methodology followed ensured that no one person came to dominate the group and allowed for all participants to obtain clarification on any of the questions. By carefully managing the possibility of groupthink, the researchers were able to explore any answers that they felt required it in more depth and to obtain inputs from the group as needed. The sequence of questions also started with more general questions to encourage the participants to share their thoughts and opinions (Waclawski \& Church, 2002).

\section{Data recording and analysis}

The thematic content analysis method was used to analyse the results of the focus groups and the interviews. Thematic content analysis is defined by Braun and Clarke (2006) as a qualitative diagnostic method for identifying, analysing and reporting on patterns or themes detected in data. Aronson (1994) describes thematic content analysis as a search for significant themes in the description of the phenomenon. In the context of organisational diagnostic approaches, the factual bases of data are established by separating the factual from the non-factual data (which comprise perceptions, skewed facts or interpretations/inferences). Confirmed facts that bear some similarity to one another are then clustered into separate categories, or groups of facts. The categories are then labelled so as accurately to depict the core character of the group of facts and clearly to differentiate one category from another (Van Tonder \& Dietrichsen, 2008).

The relationship between different categories is established by identifying a sufficiently detailed and valid diagnostic framework or model of organisational dynamics that addresses and incorporates the majority of the categories identified during the clustering process. The chosen diagnostic model or framework is then conceptually overlaid on the categorical data and the cause-effect relationships in the diagnostic model are transferred to the data. The transplanted model effectively suggests which categories are antecedents or outcomes of specific phenomena and suggests a number of more central constructs and content areas to be targeted for further measurement and analysis (Van Tonder \& Dietrichsen, 2008).

In line with the research objective, the Burke-Litwin model of organisational performance and change (Burke \& Litwin, 1992) was utilised to categorise and analyse those themes regarded as confirmed facts, which emerged from the interviews with the 11 executive managers and the employees who participated in the focus groups. In the light of the data collected, two additional themes had to be added to the Burke-Litwin model to ensure that all the feedback was adequately captured. The two themes related to transactional aspects, namely equipment and the working environment.

More specifically, during the analysis phase the following steps were used to analyse the interview data, namely:

- All the data obtained from each semi-structured interview question was typed up and listed per question

- All relevant themes regarded as confirmed facts reported per semi-structured question were tabulated

- All themes (confirmed facts) related to the scale questions (numbering 10 in total) were tabulated (in terms of a frequency count)

- No sub-group analysis was carried out, in order to maintain the confidentiality of the respondents

- The summary of the results, thus, contained both qualitative and quantitative data

- The Burke-Litwin model was populated with those core findings that were regarded as causing the effectiveness, or ineffectiveness, of the organisation

In terms of the focus groups, the following steps were followed in analysing the themes:

- The facilitator (researcher) and scribe concerned worked together to debrief their impressions and to review the postit paper responses and notes

- All those responses that were regarded as confirmed facts were then coded, according to the Burke-Litwin model for questions 2, 3 and 4

- All the responses (confirmed facts) per dimension were then tabulated, and the frequencies were counted

- The tabulated frequencies were summarised per centralised heading under each dimension of the model

- The Burke-Litwin model was populated with those core findings that were regarded as causing the effectiveness, or ineffectiveness, of the organisation

\section{Strategies employed to ensure quality data}

As depicted in Figure 2, the diagnostic process of data collection and analysis was carried out by employing a systematic action research strategy. The data collection effort was wellstructured and pursued from a platform provided in terms of a carefully considered plan and schedule, which drew on the existing knowledge of organisations in general, and the client organisation in particular. The exertion of such effort ensured that core problems and the root factors causing organisational effectiveness and ineffectiveness could be identified in a valid, reliable, accurate and unobstructed manner.

One of the shortcomings of employing a qualitative diagnostic approach is that the interpretation of data and the findings are informed or influenced by the researcher's own subjectivity (Merriam, 2002). For such a reason, the researcher might have biases that can impact significantly on the outcomes of the action research process or diagnostic effort (Merriam, 2002; Van Tonder \& Dietrichsen, 2008). Although it is difficult to eliminate such biases and subjectivities of the researcher, it is important that the researcher identifies and monitors them and considers how they may shape how he or she collects and interprets the data (Van Tonder \& Dietrichsen, 2008). To overcome any biases that can impact the results, two interviewers were used and also alternated their use of posing and probing questions. Moreover, interview schedules containing carefully worded questions were posed to the participants during both the probing interviews and the focus groups to ensure validity (that is, to elicit the desired level and range of responses) and the reliability of responses (that is, to ensure that the questions would consistently be understood in the same way by all the participants concerned) (Roodt, 2008). 


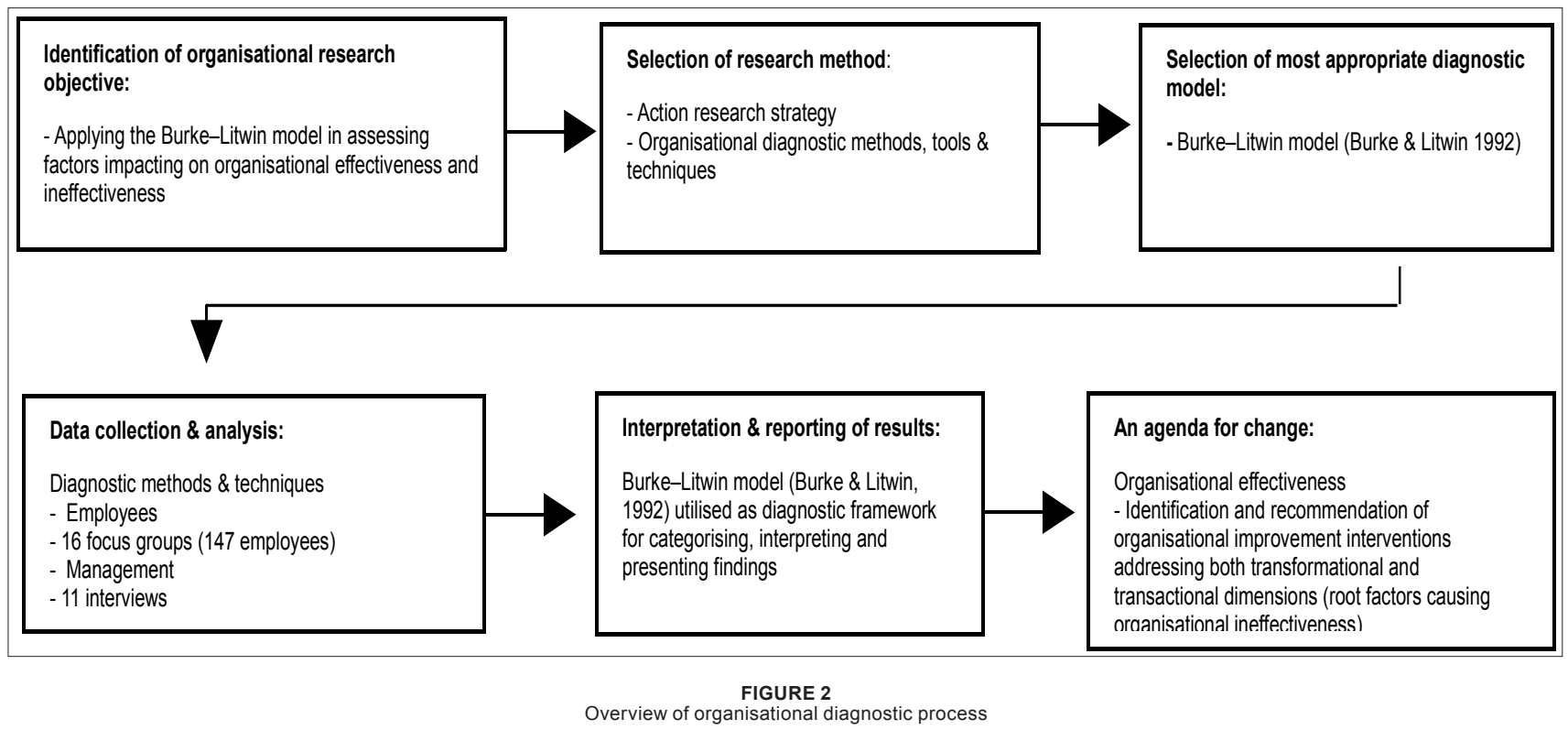

In terms of ethical considerations, it is important to note that the participants were provided with sufficient information in order that they might give their informed consent to participate in the study (Waclawski \& Church, 2002). Once such informed consent was obtained, the researchers conducted the focus groups and recorded in-depth probing interviews with the participants. The interviews were conducted individually on different days: one researcher conducted the interview, while a second researcher recorded the responses, in order to ensure impartiality and the accuracy of the data collected. For the sake of convenience and in order to guarantee a high level of privacy, the interviews were conducted in the organisation's meeting rooms. The recorded interviews and focus group results were then transcribed, analysed and categorised by employing established organisational diagnostic methods and techniques, as suggested by Van Tonder and Dietrichsen (2008).

\section{Reporting}

The personal interviews with the executive managers focused on eliciting managerial and strategic issues that might have an impact on the organisation's overall effectiveness and performance. The focus groups aimed to elicit both the transformational and transactional factors (as described by the Burke-Litwin model and as perceived by the employee participants) that were seen as affecting the organisation's overall effectiveness and performance. In analysing the data collected from both the interviews and the focus groups, general trends, similarities and differences were identified and then clustered according to the Burke-Litwin model's dimensions or categories. The adoption of such an approach enabled the researchers to view the organisational data from a multidimensional systems perspective, in terms of which the interrelationship between the themes and subthemes could be identified, analysed and understood in a systematic manner (Burke \& Litwin, 1992; Chawane et al., 2003; Cummings \& Worley, 2005).

In order to provide the client organisation with an unobstructed view of the factors affecting the organisation's effectiveness, the core findings were categorised and presented to the client organisation in terms of the Burke-Litwin model (as shown in Figure 3). In the first phase of data reporting, the themes that emerged from the four questions asked during the focus groups were reported in a tabulated format. The adoption of such a reporting approach ensured that the outcome of the data collection effort could be understood by the client organisation in terms of those factors that predict behaviour and performance consequences. They could also be linked to the root cause (organisational conditions) and effect (resultant performance) of organisational effectiveness and ineffectiveness. The results that stemmed from the four questions are reported in Tables 4 to 8 . As shown in Table 9, the client organisation was also provided with an overview of those risk-related factors that might affect the company's overall effectiveness, as well as of those aspects that could be changed to further improve the overall effectiveness of the company. The second phase of data reporting entailed categorising and populating the BurkeLitwin model with the core themes that emerged from both the interviews and the focus groups.

\section{RESULTS}

As mentioned previously, the first phase of data reporting entailed communicating the themes that emerged from the focus groups by means of tabulated format to enhance the participants' understanding of the factors that impact on both the effectiveness and the ineffectiveness of the company concerned. As shown in Tables 4 to 9, several themes, as well as a number of subthemes, emerged from the data analysis. The first question posed in the focus groups was aimed at bringing about an understanding of the aspects of importance to the respondents, that is, the desired state for optimal organisational effectiveness and performance. Table 4 shows that a total of 445 comments was received from 128 respondents. Such a finding represents $78.2 \%$ of the comments received on the characteristics of an employer of choice.

The purpose of the second question was to secure an understanding of the aspects that the participants currently enjoy at work, which could be utilised to enhance the company's current performance and effectiveness. Table 5 shows that a total of 236 comments was received. The total was found to be $53 \%$ less than the comments made about the desired state. The observation was made during the focus groups that the participants did not respond immediately to the question asked. Initially, there was silence, followed by some comments of 'nothing', or a similar expression. Some respondents than laughed uncomfortably. After additional explanation, the respondents started to write down their comments. Table 5 gives an overview of only the 12 highest ranked responses, which made up $69.5 \%$ of the comments received in connection what the employees claimed to enjoy, or what excited them about their work.

Question 3 aimed to establish what the respondents would change if they had the opportunity. The comments were then 
TABLE 4

Question 1 - Summary of themes related to characteristics of employer of choice (desired state for optimal organisational effectiveness and performance)

\begin{tabular}{|c|c|c|}
\hline THEMES & $\begin{array}{l}\text { NO. OF INDIVIDUALS WHO WROTE } \\
\text { DOWN COMMENTS ON ASPECTS }\end{array}$ & $\begin{array}{l}\% \text { OF POSSIBLE } \\
\text { RESPONDENTS }\end{array}$ \\
\hline $\begin{array}{l}\text { Motivation } \\
\text { 1. Good salary/wages compatible with production of employees and nature of work. }\end{array}$ & 78 & $60.9 \%$ \\
\hline $\begin{array}{l}\text { Task requirements and individual skills \& abilities } \\
2 . \quad \text { Company where staff development depends totally on performance/encourages and allows career growth. }\end{array}$ & 77 & $60.2 \%$ \\
\hline $\begin{array}{l}\text { Management practices } \\
\text { 3. Professional/qualified/good management, which considers the welfare and satisfaction of staff and not only } \\
\text { themselves. }\end{array}$ & 64 & $50.0 \%$ \\
\hline $\begin{array}{l}\text { External environment } \\
\text { 4. Reputation/fame/good image of company. }\end{array}$ & 47 & $36.7 \%$ \\
\hline $\begin{array}{l}\text { Management practices } \\
\text { 5. Fair management/fair treatment of staff/equal treatment/no discrimination based on nationality. }\end{array}$ & 25 & $19.5 \%$ \\
\hline $\begin{array}{l}\text { Motivation } \\
6 . \quad \text { Good staff benefits, such as insurance, bonuses, leave/housing allowance. }\end{array}$ & 22 & $17.2 \%$ \\
\hline $\begin{array}{l}\text { Task requirements and individual skills } \& \text { abilities } \\
7 . \quad \text { Opportunities for promotion/offers a rewarding future. }\end{array}$ & 18 & $14.1 \%$ \\
\hline $\begin{array}{l}\text { Climate } \\
\text { 8. Teamwork/family atmosphere. }\end{array}$ & 17 & $13.3 \%$ \\
\hline TOTAL & 348 & $78.2 \%$ \\
\hline
\end{tabular}

Note: 445 comments were received from 128 participants

TABLE 5

Question 2 - Summary of themes related to what excites participants about their work (aspects that participants enjoy at work and which can be utilised to enhance organisational effectiveness) ASPECTS

1. Good teamwork.

30

$23.4 \%$

Climate

2. Friendly staff/like those with whom I work/colleagues.

Individual \& organisational performance

3. Satisfied customers and guests/meeting with wonderful clients/different people.

4. Good management/manager is friendly/helpful/understands our problems/good relationship between management and staff.

Task requirements and individual skills \& abilities

5. I enjoy my job/am good at my job.

Task requirements and individual skills \& abilities

6. Learning new things/skills.

Work environment

7. Good work environment.

External environment

8. Good name of the company/reputation of hotel/stable organisation.

Climate

9. Family feeling/secure feeling/family atmosphere.

Motivation

10. Good salary/better wages than before.

Individual \& organisational performance

11. Continuous improvement and development of company.

Motivation

12. Receive pay/salary on time.

\begin{tabular}{cc}
14 & $10.9 \%$ \\
11 & $8.6 \%$ \\
10 & $7.8 \%$ \\
9 & $7.0 \%$ \\
8 & $6.3 \%$ \\
7 & $5.5 \%$ \\
7 & $5.5 \%$ \\
7 & $5.5 \%$ \\
\hline 164 & $69.5 \%$ \\
\hline
\end{tabular}

Note: A total of 236 comments was received. 12 themes eliciting the highest average of comments reported.

grouped per category and discussed in detail. Table 6 gives an overview of the aspects that the respondents felt strongest about changing. The fourth question focused on what the hotel is doing particularly well (that is, the actual state as experienced by the respondents). Table 7 gives an overview of those comments that were noted more than five times (86 [74.8\%] of the 115 comments received). The themes that relate to the perceived gap between the actual and desired state are summarised in Table 8. As shown in Table 9, all the responses from the executive managers obtained by means of the personal interviews were classified and categorised as potential risks for the hotel.

The second phase of data reporting entailed categorising and populating the Burke-Litwin model with the core themes that had emerged from both the interviews and the focus groups. The
Burke-Litwin model was then used as a diagnostic framework to communicate the overall results to the participants.

The findings (as summarised in Figure 3) show that both transformational and transactional factors appear to be affecting the organisation's overall effectiveness, in either a positive or negative manner. The observation is supported by the themes that emerged from the risk analysis outlined in Table 9 , as well as by the gaps identified by means of an analysis of the respondents' experiences of the desired and actual states (as outlined in Table 8).

In observing Figure 3, the following findings were derived from the diagnostic effort. 
TABLE 6

Question 3 - Summary of themes related to what staff would like to change

\begin{tabular}{|c|c|c|}
\hline COMMENT & $\begin{array}{r}\text { NO. OF INDIVIDUALS WHO } \\
\text { WROTE DOWN COMMENTS ON } \\
\text { ASPECTS }\end{array}$ & FREQUENCY \\
\hline $\begin{array}{l}\text { Individual and organisational performance } \\
\text { 1. Salary; benefits; overtime; grading; recognition; working hours; performance appraisal. }\end{array}$ & 178 & $121 \% *$ \\
\hline $\begin{array}{l}\text { Task requirements and individual skills \& abilities } \\
\text { 2. Promotions; training and development; skills and abilities; recruitment. }\end{array}$ & 100 & $68 \%$ \\
\hline $\begin{array}{l}\text { Systems, policies and procedures } \\
\text { 3. HR systems; SOPs; grievance; discipline. }\end{array}$ & 51 & $34.7 \%$ \\
\hline $\begin{array}{l}\text { Culture } \\
\text { 4. Fair treatment }\end{array}$ & 50 & $34.0 \%$ \\
\hline $\begin{array}{l}\text { Work environment } \\
\text { 5. Buildings; offices; cafeteria; furniture. }\end{array}$ & 37 & $25.2 \%$ \\
\hline $\begin{array}{l}\text { Management practices } \\
6 . \quad \text { Communication; change in the way of management, etc. }\end{array}$ & 35 & $23.8 \%$ \\
\hline TOTAL & 451 & \\
\hline
\end{tabular}

Note: Some respondents referred to more than one aspect in a particular category (i.e. the number of comments exceeds the number of participants)

TABLE 7

Question 4 - Summary of themes related to what the hotel excels at (actual state)

\begin{tabular}{|c|c|c|}
\hline & $\begin{array}{r}\text { NO. OF INDIVIDUALS WHO } \\
\text { WROTE DOWN COMMENTS } \\
\text { ON ASPECTS }\end{array}$ & $\begin{array}{l}\% \text { OF POSSIBLE } \\
\text { RESPONSES }\end{array}$ \\
\hline $\begin{array}{l}\text { Work environment } \\
\text { 1. Upgrading hotel facilities/car park/renovating rooms/keeping on changing and upgrading/upgrading outlets/creating } \\
\text { new looks and keeping changing image of the hotel by creating new looks. }\end{array}$ & 19 & $22.3 \%$ \\
\hline $\begin{array}{l}\text { External environment } \\
2 \text {. Good image of hotel/good hotel facilities/good location/impression/uniforms, etc. }\end{array}$ & 17 & $20.0 \%$ \\
\hline $\begin{array}{l}\text { External environment } \\
\text { 3. Very good profit/good business/good market share in terms of occupancy. }\end{array}$ & 15 & $17.6 \%$ \\
\hline $\begin{array}{l}\text { Work environment } \\
4 . \quad \text { Good restaurants/high quality of food presentation/variety of restaurants. }\end{array}$ & 10 & $11.7 \%$ \\
\hline $\begin{array}{l}\text { Motivation } \\
5 . \quad \text { Yearly bonus. }\end{array}$ & 8 & $9.4 \%$ \\
\hline $\begin{array}{l}\text { External environment } \\
6 . \quad \text { Addressing the needs of customers/guests/treating customers well/good service. }\end{array}$ & 6 & $7.1 \%$ \\
\hline $\begin{array}{l}\text { Motivation } \\
7 . \quad \text { Paying salaries on time. }\end{array}$ & 6 & $7.1 \%$ \\
\hline $\begin{array}{l}\text { Management practices } \\
\text { 8. Good management/long-standing Bahraini management appreciates long-service employees. }\end{array}$ & 5 & $5.9 \%$ \\
\hline TOTAL & 86 & $74.8 \%$ \\
\hline
\end{tabular}

TABLE 8

Gap between actual and desired states, as perceived by participants

\begin{tabular}{|c|c|c|c|}
\hline DESIRED & & ACTUAL & \\
\hline What would staff chan & & What is the hotel doin & ell? \\
\hline $\begin{array}{l}\text { - Individual and organisational } \\
\text { performance }\end{array}$ & $-12.1 \%$ & $\begin{array}{l}\text { - Salaries paid on } \\
\text { time/ yearly bonus }\end{array}$ & $+16.5 \%$ \\
\hline $\begin{array}{l}\text { - Task requirements and } \\
\text { individual skills and abilities }\end{array}$ & $-68 \%$ & -Employee training & $+4.7 \%$ \\
\hline $\begin{array}{l}\text {-Systems, policies and } \\
\text { procedures }\end{array}$ & $-34.7 \%$ & - No comments & $+0 \%$ \\
\hline - Culture & $-34 \%$ & $\begin{array}{l}\text {-Addressing needs of } \\
\text { customers }\end{array}$ & $+7.1 \%$ \\
\hline -Management practices & $-23.8 \%$ & - Good management & $+5.9 \%$ \\
\hline -Working environment & $-25.2 \%$ & $\begin{array}{l}\text { - Good image; upgrading } \\
\text { of hotel }\end{array}$ & $+42.3 \%$ \\
\hline & & - Good business/profit & $+17.6 \%$ \\
\hline & & - Good restaurants & $+11.7 \%$ \\
\hline & & $\begin{array}{l}\text { - Focus on customer } \\
\text { service }\end{array}$ & $+71.4 \%$ \\
\hline
\end{tabular}

Notes:

(1) * Perceptions of customers

(2) What staff would change refers to their experience

(3) Percentages refer to the number of possible comments

(4) + Refers to positive factors (factors regarded as sources of organisationa

effectiveness)

(5) - Refers to negative/developmental factors (factors regarded as sources of organisational ineffectiveness)
TABLE 9

Risks identified - themes related to executive managers' responses

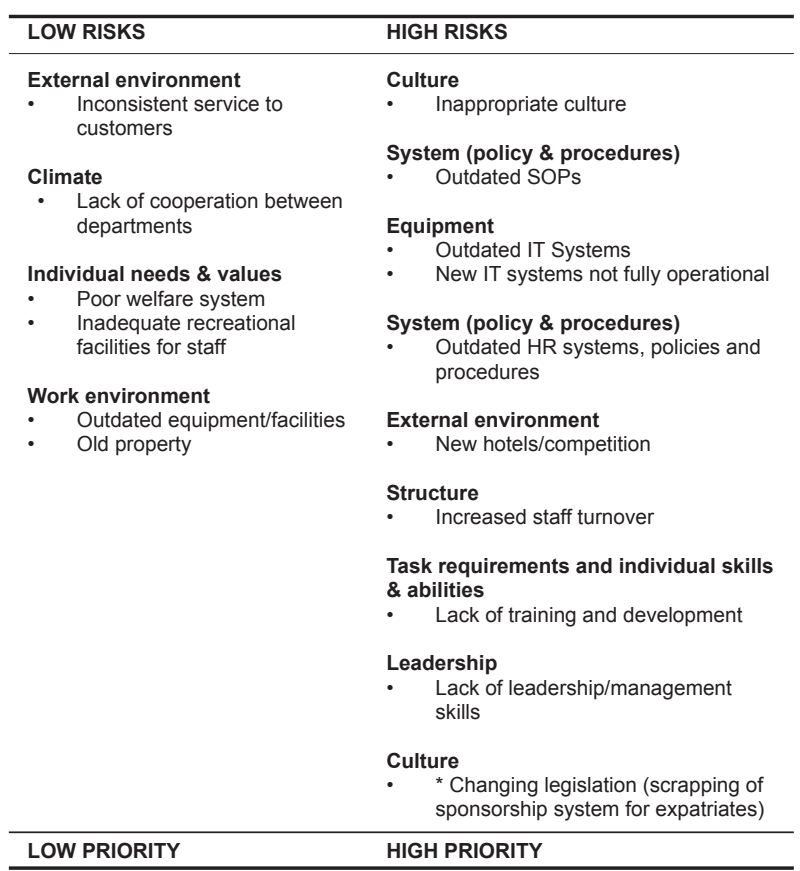




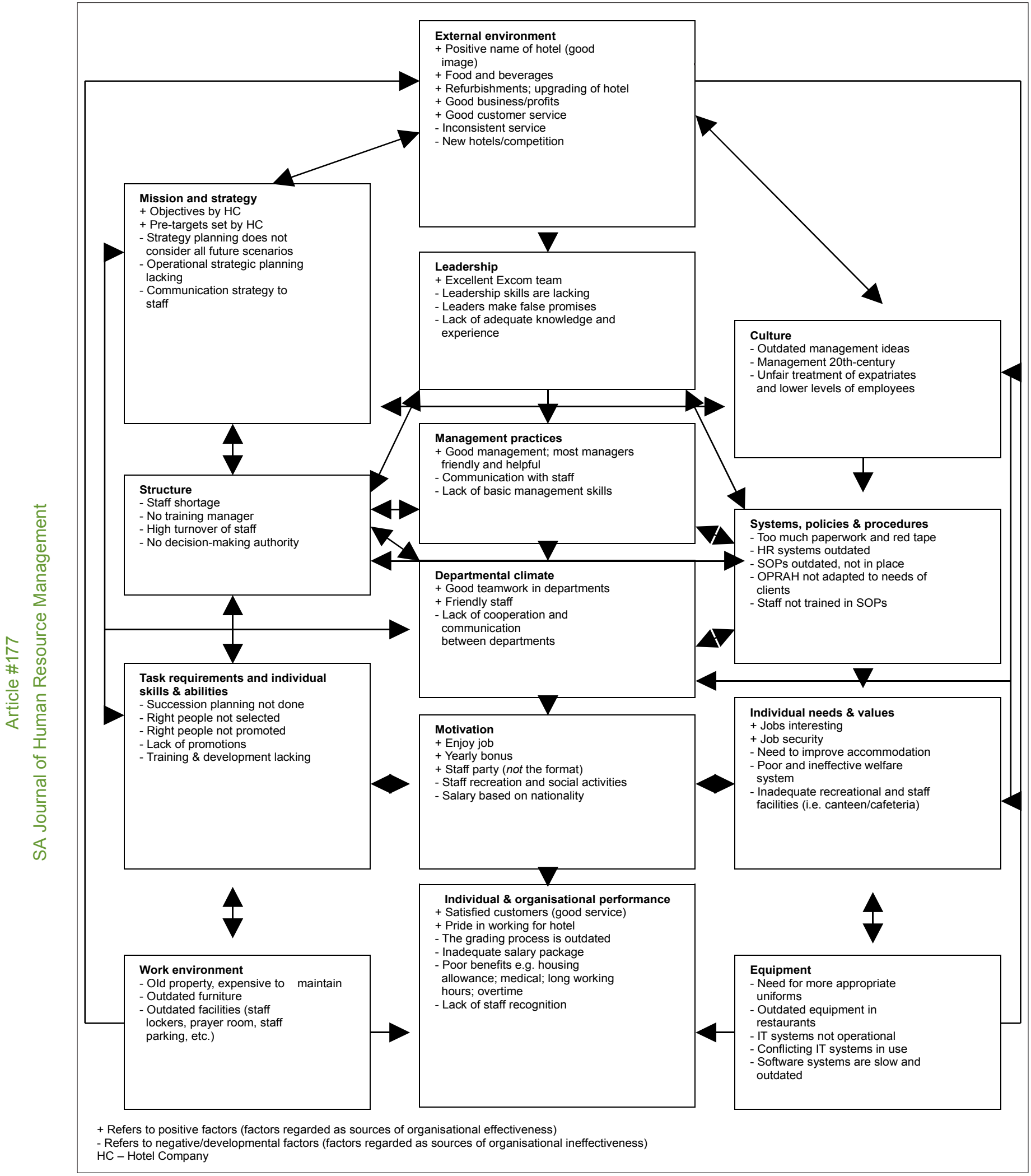

- Refers to negative/developmental factors (factors regarded as sources of organisational ineffectiveness)

FIGURE 3

Summary of organisational diagnosis outcome (interviews and focus groups)

Transformational factors affecting organisational performance and effectiveness

The first findings that could be drawn from applying the organisational diagnostic approach resulted from identifying those factors that were seen to affect the organisation's effectiveness at the transformational level of the Burke-Litwin model. Such factors were found to include the following:
- A number of positive conditions were apparent in the external environment dimension, namely the positive reputation of the hotel, the food and beverage supplied, the refurbishments of the hotel and the good business/profits obtained. Such factors were regarded as highly visible and tangible conditions. 
- With regards to the dimension of vision, mission and strategy, both the objectives and targets appeared to be welldefined. The strategic planning, however, was reported as not taking into consideration all future scenarios, operational planning appeared to be lacking and the strategy was not communicated to the staff.

- The analysis indicated an excellent Excom team. Leadership skills, however, were found to be lacking, false promises were reported as having been made and the leaders and/ or managers seemed to lack adequate knowledge and experience.

- The results indicated a culture characterised by outdated management ideas. Such a culture was perceived as having given rise to the unfair treatment of employees, particularly that of expatriates and employees at the lower levels of the organisation.

- The results of the individual and organisational performance dimension show that the customers are perceived as being satisfied, resulting in a sense of pride in working for the hotel. Areas identified for improvement related to dissatisfaction with certain aspects that impact directly on individual performance, such as the adherence to an outdated performance process, the receipt of an inadequate salary package and a lack of staff recognition.

The respondents mentioned the following perceptions related to the unique features of the company culture, namely that the hotel:

- Is the only international hotel with a local flavour

- Has a family culture, with friendly staff

- Offers the best food and beverages in the city

- Has changed over the years, in order to allow its employees to have more authority

- Is old-fashioned in the services that it provides (such as those of a tailor, butlers, and a 24-hour cleaning service)

- Is staffed by employees who do not accept change easily

- Still uses outdated internal processes

- Is part of a stable company, and

- Allows few opportunities for creativity and innovation.

The reasons for the positive responses appeared to relate to the renovations and new extensions to the hotel, with the new restaurants and company being the least affected by market changes brought about by the Iraqi war.

\section{Transactional factors affecting organisational performance and effectiveness}

The findings of the current research study show that problematic issues related to the transactional factors included such issues as organisational structure, task requirements and individual skills and abilities, working environment, organisational systems (as set out in the hotel's policies and procedures), and work-related equipment. Such factors could, therefore, have a potentially negative impact on the organisation's overall effectiveness and bottom-line performance. They were also indicated as riskrelated factors by the participants. Tables 4 to 7 show that the respondents reported both positive and negative experiences related to transactional factors, such as management practices, departmental climate, motivation and individual needs and values. As shown in Table 8, the gap analysis between the actual and desired states, as perceived by the respondents, indicates specific aspects related to task requirements, individual skills and abilities, management practices and the work environment, which were all seen to affect the organisation's overall effectiveness. The findings also suggest that the respondents aspired to work for a company that gave priority to factors related to employee motivation (such as salary, benefits and working hours) and employee training and development.

\section{DISCUSSION}

As stated, the main purpose of the current study was to apply the Burke-Litwin model as a diagnostic framework for assessing factors that affect the effectiveness or ineffectiveness of an organisation. Generally, the findings seemed to show that the Burke-Litwin model (Burke \& Litwin, 1992) provides a convenient and valid shorthand method of identifying and explaining multiple key organisational phenomena that affect the organisation's performance and overall effectiveness.

As has been observed by other researchers in the past, including Howard (1994), the Burke-Litwin model appears to be an extremely useful framework for diagnosing and planning change from a multidimensional systems perspective. In this regard, Howard (1994), for instance, discusses three examples in which the Burke-Litwin model was used and applied with success, namely in studies of British Airways (BA), a large governmentsponsored organisation in Europe, and the National Aeronautics and Space Administration (NASA). The unique features of the company (including its cross-cultural research setting) and its relationship with its particular external and macro environment were taken into account in the interpretation of the findings.

Figure 3 shows some significantly positive outcomes for the transformational dimensions of external environment, and mission and strategy, as well as for the transactional dimensions of climate, motivation, and employees' individual needs and values. The transformational dimensions of leadership skills, culture, and individual and organisational performance appeared to be experienced as problematic and, thus, in need of organisational improvement interventions. In this regard, Burke and Litwin (1992) suggest that interventions aimed at improving the transformational dimension should first be attempted before considering undertaking changes at the transactional level in order to bring about genuine change in the overall effectiveness of an organisation's performance. Interventions aimed at addressing factors that relate to the transformational dimension of organisational effectiveness create the foundation for those changes that need to be implemented with regard to the transactional dimensions (French \& Bell, 1999; Jones \& Brazzel, 2006). Research undertaken by Kraut (1996) shows that interventions focused on the transformational dimension of mission and strategy, and the transactional dimensions of task requirements, management practices, and individual needs and values, tend to have a positive influence on individual and organisational performance.

In the context of the current study, it appears that the OD interventions aimed at bringing about the desired change in the strategic and operational planning processes, the staff communication strategies, the leader/management style and competence, and the staff compensation, reward and recognition practices might help to improve the overall employee satisfaction experienced as a precursor to organisational performance (Riordan, Vandenberg \& Richardson, 2005). The research undertaken by Eskildsen and Dahlgaard (2000) also showed that an organisation can improve employees' satisfaction by focusing on factors that impact on organisational performance, such as le ader competence and behaviour, management practices and processes that enhance employees' feelings and perceptions of empowerment, involvement, recognition and growth opportunities. Findings of employee satisfaction studies indicate a link between profitability, productivity, employee retention and customer satisfaction. Satisfied, motivated employees generally seem to create higher levels of customer satisfaction and, in turn, positively influence organisational performance (Wan, 2007).

The transactional dimension of organisational effectiveness relates to factors that affect the everyday interactions and exchanges that create the general climate of an organisation. According to Burke and Litwin (1992), the transactional factors (consisting of employees' impressions, expectations and feelings) impact on organisational relationships. The factors that appear to have the most negative impact on the levels of employees' satisfaction (and, thus, potentially on an organisation's performance) relate to inadequacies in systems (such as outdated policies and procedures), equipment, 
structure, task requirements, and individual skills and abilities (relating to staff capacity and competence). Research by Wan (2007) shows that when employees receive career growth opportunities, including opportunities for improving their skills and for working with up-to-date technologies, they tend to exhibit high levels of satisfaction. Lack of job-related skills and outdated technologies tend, in contrast, to jeopardise levels of efficiency and to lead to the wastage of resources. Such factors generally affect organisational bottom-line performance.

The results of the current study also indicate that factors related to organisational climate, namely a lack of cooperation and communication between departments, require attention. Agho, Mueller and Price (1993) found, in this regard, that working with friendly people (in the form of cohesive work groups) has an impact on employee satisfaction. Similarly, research by Spector (1997) shows the importance of interpersonal relationships for employee satisfaction. Research by Stavrou-Costea (2005) shows that an organisational climate and a business culture conducive to continuous training and development generally increases levels of efficiency and flexibility. In addition, such a culture and climate also appear to facilitate the development of the requisite employee relations, which, in turn, tend to result in greater productivity, better service quality and increased profitability in organisations.

\section{Implications for management}

The findings of the current study indicate that using an opensystems-based diagnostic framework, such as the Burke-Litwin model, can provide an organisation with a valid, accurate and clear picture of the factors that affect its effectiveness, as experienced by all relevant stakeholder groups. In diagnostic action research, the OD practitioner enters a problem situation, diagnoses the problem, and makes recommendations for the remedial treatment of the organisation (French \& Bell, 1999). Moreover, organisations are generally regarded as complex social systems, which interact with the environment in a unique context. Interventions aimed at change usually focus on improving those aspects that are regarded as the major sources of organisational ineffectiveness and which appear to affect large parts of the organisation (French \& Bell, 1999). Therefore, based on the findings, it is recommended that the company's broad intervention plans address both transformational and transactional aspects, as indicated below.

\section{Transformational factors}

It is recommended that management:

- Clarify the culture of the organisation and embark on a process to embed the new culture

- Develop a leadership model based on the organisational culture and develop the relevant managers accordingly

- Conduct strategic planning and focus on all possible future scenarios.

\section{Transactional factors}

It is recommended that management:

- Revise the organisational structure of the organisation to support the culture

- Implement succession planning, with all its supporting facets

- Revise all systems, policies and procedures

- Audit and update the work environment and equipment

- Implement teambuilding between departments to improve the levels of cooperation and communication

- Investigate the current lack of recognition, including the perceived inadequate recognition of performance

- Improve the organisation's employee wellness system.

It is recommended that the organisation firstly focus on the transformational factors, as such factors are likely to have the greatest influence on organisational performance. Kraut (1996) found that the most significant improvements in performance ratings were likely to be achieved by concentrating on factors of mission and strategy, organisational culture, management practices and work climate, whereas improvements in people's motivation had more to do with factors of job/skills match, individual needs and values and organisational processes and systems. In terms of the current study, the Excom team of the hotel decided to follow the approach recommended by the OD consultants. Further to an in-depth discussion of the diagnoses and recommendations, the Excom team of the hotel decided to follow the approach recommended by the consultants, namely to first focus on the transformational factors and secondly on the transactional factors. The first step taken was to conduct a strategic planning and change workshop, to plan, and prioritise actions and secondly to workshop the proposals and the impact on business plan and budgets.

\section{Conclusion}

The value of the current study clearly lies in the richness of the data obtained in the cross-cultural research setting, by means of the diagnostic methods, techniques and process employed for such a purpose. The systematic action research procedure followed in gathering data for the purpose of organisational diagnosis, as well as the utilisation of the Burke-Litwin model as a diagnostic framework for categorising and analysing the collected data, contributed to an increase in the validity and reliability of the organisational diagnosis process and outcomes concerned.

Apart from increasing the involvement of employees and management, and, therefore, the ownership of data, the organisational diagnostic process, model and techniques employed also helped to create a very strong platform for future organisational improvement actions. One of the most valuable outcomes of the use of the diagnostic approach was the expanded conceptual map or picture that the client organisation developed of itself as a result of using the Burke-Litwin model in reporting and presenting the recorded data.

As with all research, the current study has limitations. First and foremost, it must be noted that, due to the qualitative nature of the diagnostic approach followed, the present study's results cannot be generalised to all kinds of organisation. The main limitation of the study was, arguably, the use of a single model within a single social context. In this regard, Shirom and Harrison (1995) emphasise that no single model can fit all diagnostic situations for all client organisations. Chawane et al. (2003) also question the weighting of transformational factors as more fundamental when planning change interventions, particularly when considering the reciprocity of the Burke-Litwin model components. Caution should, therefore, be taken not to interpret the findings as meaning that the transformational factors are more important than the transactional factors in planning change. In conclusion, it is recommended that more diagnostic research be conducted in a variety of social contexts so as better to illuminate those factors affecting organisational effectiveness. Quantitative research should also be undertaken to measure the magnitude of the identified factors as regards the overall effectiveness and bottom-line performance of the organisation in question.

\section{REFERENCES}

Agho, A.O., Mueller, C.W., \& Price, J.L. (1993). Determinants of employee job satisfaction: An empirical test of a causal model. Human Relations, 46(8), 1007-1125.

Aronson, A. (1994). A pragmatic view of thematic analysis Qualitative Report, 2(1), 1.

Baker, G., \& Maddux, H. (2005). Enhancing organisational performance: Facilitating the critical transition to a process view of management. SAM Advanced Management Journal, 70(4), 43-60.

Banister P., Burman, E., Parker, I., Taylor, M., \& Tindall, C. (1994). Qualitative methods in psychology: A research guide. Birmingham: Open University Press. 
Baruch,Y.,\& Ramalho,N.(2006).Communalitiesand distinctions in the measurement of organisational performance and effectiveness across for-profit and nonprofit sectors. Nonprofit and Voluntary Sector Quarterly, 35(1), 39-65.

Braun, V., \& Clarke, V. (2006). Doing thematic analysis in psychology. Qualitative Research in Psychology, 1(3), 77-101.

Burke, W.W., \& Litwin, G.H. (1992). A causal model of organisational performance and change. Journal of Management, 8(3), 523-546.

Chawane, T., Van Vuuren, L.J., \& Roodt, G. (2003). Personal change as a key determinant of the outcomes of organisational transformation interventions. SA Journal of Human Resource Management, 1(3), 62-76.

Cummings, T.G., \& Worley, C.G. (2005). Organisation development and change. (8th edn.). Mason: Thomson South Western.

Eskildsen, J.K., \& Dahlgaard, J.J. (2000). A causal model for employee satisfaction. Total Quality Management, 11(8), 10811094.

French, W.L., \& Bell, C.H. (1999). Organizational development: Behavioural science interventions for organisational improvement. (6th edn.). Englewood Cliffs: Prentice-Hall.

Furnham, A., \& Gunter, B. (1993). Corporate assessment: Auditing a company's personality. London: Routledge.

Henning, E., Van Rensburg, W., \& Smit, B. (2004). Finding your way into qualitative research. Pretoria: Van Schaik.

Howard, A. (1994). Diagnoses for organization change: Methods and models. New York: Guilford Press.

Huselid, M.A.(1995). Theimpact of human resourcemanagement practice on turnover, productivity and corporate financial performance. Academy of Management Journal, 38(3), 635672.

Jackson, L. (2008). Client systems: Entry, contracting, action planning and termination. In C.L. van Tonder \& G. Roodt (Eds.), Organisation development: Theory and practice, (pp.123132). Pretoria: Van Schaik.

Jones, B.B., \& Brazzel, M. (2006). The NTL handbookoforganizational development and change: Principles, practices and perspectives. San Francisco: Pfeiffer.

Kontoghiorghes, C., Awbrey, S.M., \& Feurig, P.L. (2005). Examining the relationship between learning organisation characteristics and change adaptation, innovation and organisational performance. Human Resource Development Quarterly, 16(2), 185-211.

Kraut, A.I. (1996). Organizational surveys: Tools for assessment and change. San Francisco: Jossey Bass.

Lee, D., \& Brower, R.S. (2006). Pushing the envelope on organisational effectiveness. Public Performance $\mathcal{E}$ Management Review, 30(2), 155-178.
Merriam, S.B. (2002). Qualitative research in practice: Examples for discussion and analysis. San Francisco: John Wiley.

Ostroff, C. (1995). SHRM/CCH survey. Human Resource Management: Ideas and Trends in Personnel, 365, 1-12.

Riordan, C.M., Vandenberg, R.J., \& Richardson, H.A. (2005). Human Resource Management, 44(4), 471-488.

Roodt, G. (2008). Survey research and data feedback. In C.L. van Tonder \& G. Roodt (Eds.), Organisation development: Theory and practice, (pp. 251-268). Pretoria: Van Schaik.

Rosnow, R.L., \& Rosenthal, R. (1996). Beginning behavioural research: A conceptual primer. (2nd edn.). Englewood Cliffs: Prentice Hall.

Rothwell, W.J., \& Sullivan, R.L. (2005). Practicing organization development: A guide for consultants. San Francisco: Pfeiffer.

Schurink, W.J. (2003). Qualitative research in management and organizational studies with reference to recent South African research. SA Journal of Human Resource Management, 1(3), $2-14$.

Shirom, A., \& Harrison, M.I. (1995). Diagnostic models for organisations: Toward an integrative perspective. In C.L. Cooper \& D.M. Rousseau (Eds.), Trends in Organisational Behaviour, Vol. 2 (pp. 85-107). New York: Wiley.

Slocum, J.W., \& Hellriegel, D. (2007). Fundamentals of organisational behaviour. Mason: Thomson South Western.

Smith, J.A. (2003). Qualitative psychology. A practical guide to methods. London: Sage.

Spector, P.E. (1997). Job satisfaction: Application, assessment, causes and consequences. Thousand Oaks: Sage.

Stavrou-Costea, E. (2005). The challenge of human resource management towards organizational effectiveness: A comparative study in Southern EU. Journal of European Industrial Training, 29(2), 112-134.

Struwig, F.W., \& Stead, G.B (2001). The psychology and management of workplace diversity. Malden: Blackwell.

Van Tonder, C., \& Dietrichsen, P. (2008). The art of diagnosis. In C.L. van Tonder \& G. Roodt (Eds.), Organisation development: Theory and practice (pp.133-166). Pretoria: Van Schaik.

Waclawski, J., \& Church, A.H. (2002). Organizational development: A data-driven approach to organizational change. Boston: JosseyBass.

Wan, H.L. (2007). Human capital development policies: Enhancing employees' satisfaction. Journal of European Industrial Training, 31(4), 297-322.

Welman, J.C., \& Kruger, S.J. (2001). Research methodology (2nd edn.). Cape Town: Oxford University Press.

Whitfield, G., \& Landeros, R. (2006). Supplier diversity effectiveness: Does organizational culture really matter? The Journal of Supply Chain Management: A Global Review of Purchasing and Supply, 42(4), 16-27. 